\title{
DETERMINAÇÃO DO TEOR DE CLORETO EM ÁGUAS DE ABASTECIMENTO DA REGIÃO AGRESTE POTIGUAR
}

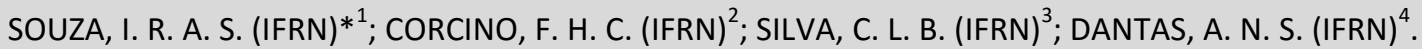

\section{RESUMO}

O cloreto é o ânion inorgânico mais frequente em águas naturais. O sabor salgado conferido pelo cloreto depende da concentração da espécie bem como da composição da água. Algumas águas que contêm teores acima de $250 \mathrm{mg} \mathrm{L-1}$ deste analito apresentam sabor salgado quando o cátion associado é o sódio. O limite da concentração de ingestão é de $400 \mathrm{mg} \mathrm{L-1.} \mathrm{A} \mathrm{partir} \mathrm{de} 500$ mg L-1 esta espécie começa a apresentar influêmcia biológica. Desta maneira, dependendo da concentração o cloreto pode causar problemas ao ser humano e, por isso, deve-se ter um controle com a sua utilização.
Pensando nisso, por meio de análises volumétricas, foi verificado o teor de cloreto nas águas das cidades de Nova Cruz, Santo Antônio, Várzea, Passa e Fica, Serrinha, Lagoa d'Anta, Campestre, Montanhas e Espírito Santo. Os quais tiveram os resultados em $\mathrm{mg} / \mathrm{L}$, respectivamente, equivalentes a 40,$88 ; 35,07$; 52,$54 ; 55,21 ; 35,14 ; 106,71 ; 53,36 ; 61,68 ; 57,68$. Concluindo assim, que todas as cidades apresentaram uma água confiável e apropriada para ser utilizada, uma vez que não viola a Lei imposta pelo Ministério da Saúde (menor que $250 \mathrm{mg} / \mathrm{L}$ ).

PALAVRAS-CHAVE: Teor de cloreto, água, método de Mohr.

\section{DETERMINATION OF CHLORIDE CONTENT IN WATER SUPPLY OF THE AGRESTE POTIGUAR REGION}

\begin{abstract}
Chloride is the most common inorganic anion in natural waters. The salty flavor conferred by chloride depends on the concentration of species and the composition of the water. Some waters containing levels above $250 \mathrm{mg} \mathrm{L-1}$ of the analyte present salty taste when the associated cation is sodium. The threshold concentration is the ingestion of $400 \mathrm{mg} \mathrm{L}-1$. From $500 \mathrm{mg} \mathrm{L-1}$ this species begins to exhibit biological influêmcia. Thus, depending on the concentration of chloride may cause problems to humans and, therefore must have a control with its
\end{abstract}

use. Thinking about it, by volumetric analysis, it was found the chloride content in the water of the cities of New Cross, St. Anthony, Lowland, Passa e Fica, Serrinha, Lagoa d'Anta, Campestre, Mountains and Holy Spirit. The results which were in $\mathrm{mg} \mathrm{/} \mathrm{L}$, respectively, equivalent to $40.88 ; 35.07 ; 52.54 ; 55.21$; $35.14 ; 106.71 ; 53.36 ; 61.68 ; 57.68$. Thus concluding that all cities had a reliable and adequate water to be used as it does not violate the law imposed by the Ministry of Health (less than $250 \mathrm{mg} / \mathrm{L}$ ).

KEY-WORDS: Chloride content, water, method of Mohr. 


\section{QU}

\section{DETERMINAÇÃO DO TEOR DE CLORETO EM ÁGUAS DE ABASTECIMENTO DA REGIÃO AGRESTE POTIGUAR}

\section{INTRODUÇÃO}

Atualmente, as águas fornecidas pelas concessionárias passam por processos de filtração, em que utiliza-se produtos químicos como uma forma de tratamento para combater a contaminação de esgotos, depósitos de lixo, vazamentos de combustíveis, entre outros efluentes que acabam mudando a composição da água com a infecção de germes, bactérias, coliformes fecais e microorganismos.

O principal componente utilizado nessas estações de tratamento são os compostos a base de cloro, tornando a água extremamente tóxica para todos os organismos vivos. Esse elemento químico forma o ácido clorídrico que a partir dele deriva-se o sal/ânion cloreto, composto que em contato com a pele e os olhos, pode causar irritações e até mesmo queimaduras, além de outros males a saúde em casos de ingestão [1].

Por esse motivo, a Portaria no 518/2004 do Ministério da Saúde impõe um controle desse teor, de modo que o máximo permitido é de $250 \mathrm{mg} / \mathrm{L}$ [2]. Assim, com base nessa referência e em conceitos da química analítica quantitativa, foram realizadas análises volumétricas (titulação de precipitação através do método de Mohr) com águas residuais disponíveis em diferentes municípios da região, tendo como objetivo certificar se as mesmas estão dentro dos padrões permitidos. Uma vez que, a química analítica fundamenta-se na determinação da composição da matéria, sendo a qualitativa aquela que identifica as espécies atômicas, e a quantitativa, a que afirma as quantidades relativas de um ou mais componentes dessa solução [3].

\section{MATERIAIS E MÉTODOS}

\subsection{Preparo e padronização das soluções}

Todo o material foi previamente lavado antes da realização dos procedimentos experimentais. Em seguida, foram preparadas soluções de $\mathrm{NaCl}$ e $\mathrm{AgNO}_{3}$, ambas na concentração $0,05 \mathrm{~mol} \mathrm{~L}^{-1}$. As massas dos reagentes foram pesadas e diluidas utilizandose um balão volumétrico de $100 \mathrm{~mL}$. Para padronizar o $\mathrm{AgNO}_{3}$, adicionou-se uma alíquota de $10 \mathrm{~mL}$ da solução de $\mathrm{NaCl}$ 0,05M, juntamente com 1 gota de cromato de potássio $5 \%$ (indicador) em um erlenmeyer, sendo esta alíquota titulada com a solução de nitrato de prata até a observação da formação de um precipitado avermelhado, indicando o ponto final da titulação (estimativa do ponto de equivalência). O volume gasto de $\mathrm{AgNO}_{3}$ foi utilizado para calcular a real concentração desta solução.

\subsection{Determinação do teor de cloreto em amostras de águas de cidades da região agreste potiguar}

As amostras de águas foram coletadas em nove cidades da região agreste potiguar, sendo elas: Campestre, Espírito Santo, Lagoa d'Anta, Montanhas, Nova Cruz, Passa e Fica, Santo Antônio, Serrinha e Várzea. As amostras de água foram coletadas em garrafas PET previamente lavadas. Após a coleta, as amostras foram levadas para o IFRN Campus Nova Cruz e analisadas no Laboratório de Química Analítica Quantitativa. No momento das análises a temperatura ambiente era de $24^{\circ} \mathrm{C}$. Para tanto, uma alíquota ( $\mathrm{n}$ = 3) de $10 \mathrm{~mL}$ de cada amostra de água foi titulada com a solução de $\mathrm{AgNO}_{3}$, previamente 


\section{QU}

padronizada, até o surgimento de um precipitado de coloração avermelhada.

\section{RESULTADOS E DISCUSSÕES}

\subsection{Padronização da solução de $\mathrm{AgNO}_{3} \mathrm{0,05M}$}

A titulação de precipitação serve para determinar a concentração em mol/L de alguma solução baseando-se na formação de compostos pouco solúveis, em que o ponto de viragem pode ser identificado pela simples visualização do momento em que deixa de ocorrer precipitação [4].

Uma desvantagem desse processo é que, às vezes, a reação envolvida não oferece condições para uma conveniente sinalização do ponto de viragem e, por isso, existem três métodos distintos para essa determinação volumétrica.

A técnica usada na metodologia do referido projeto foi o método de Mohr, o qual utiliza o indicador $\mathrm{K}_{2} \mathrm{CrO}_{4}$ que ao reagir com o $\mathrm{AgNO}_{3}$, de acordo com a equação (1), origina um precipitado vermelho que torna perceptível o momento do ponto de equivalência.

$$
\mathrm{Ag}^{+}{ }_{(\mathrm{aq})}+\mathrm{NO}_{3}^{-}{ }_{(\mathrm{aq})}+2 \mathrm{~K}_{(\mathrm{aq})}{ }^{+}+\mathrm{CrO}_{4(\mathrm{aq})}{ }^{2-} \rightarrow \mathrm{Ag}_{2} \mathrm{CrO}_{4(\mathrm{~s})}+\mathrm{NO}_{3}^{-}{ }_{(\mathrm{aq})}+2 \mathrm{~K}^{+}{ }_{(\mathrm{aq})} \quad \text { Equação (1) }
$$

A visualização da cor vermelha nos repassa a informação de que não há mais formação do precipitado $\mathrm{AgCl}$, de acordo com a equação (2), pois como esse composto possui solubilidade menor do que a do $\mathrm{Ag}_{2} \mathrm{CrO}_{4}$, o mesmo se precipita primeiro e somente depois de todo o $\mathrm{Cl}^{-}$reagir com o íon $\mathrm{Ag}^{+}$, o sólido vermelho é formado (equação 1) [5].

$$
\mathrm{Ag}_{(\mathrm{aq})}^{+}+\mathrm{NO}_{3}^{-}{ }_{(\mathrm{aq})}+\mathrm{Na}_{(\mathrm{aq})}^{+}+\mathrm{Cl}_{(\mathrm{aq})}^{-} \rightarrow \mathrm{AgCl}_{(\mathrm{s})}+\mathrm{NO}_{3}^{-}{ }_{(\mathrm{aq})}+\mathrm{Na}^{+}{ }_{(\mathrm{aq})} \quad \text { Equação (2) }
$$

Dessa forma, como a reação principal do processo tem uma proporção estequiométrica de 1 para 1 (equação 2), pode-se afirmar que o número de mol do íon $\mathrm{Ag}^{+}$é igual a quantidade de mols de $\mathrm{Cl}^{-}$presente na solução titulada, de modo que ao relacionar o volume gasto do titulante (tabela 1), aproximadamente $10,13 \mathrm{~mL}$, na fórmula de diluição de soluções, sabendo que foi usado $10 \mathrm{~mL}$ de uma solução de $\mathrm{NaCl} 0,0507 \mathrm{M}$, têm-se que a concentração do $\mathrm{AgNO}_{3}$ utilizado é igual a 0,0501 mol L-1. Tendo assim um percentual de erro para essa concentração, considerado muito baixo, de valor igual a $0,2 \%$.

Tabela 1: Volume gasto do reagente $\mathrm{AgNO}_{3}$ na padronização do mesmo.

\begin{tabular}{cc}
\hline Titulação & Volume gasto de $\mathrm{AgNO}_{3}(\mathrm{~mL})$ \\
\hline 1 a & 10,1 \\
2 a & 10,1 \\
3 a & 10,2 \\
\hline
\end{tabular}

3.2. Determinação do teor de cloreto em amostras de águas de cidades da região agreste potiguar

Da mesma forma que foi determinada a concentração da solução de nitrato de prata, reagindo o íon prata com o ânion $\mathrm{Cl}^{-}$, foi descorberto o teor de cloreto em amostras de águas coletadas de casas de cidades distintas. De modo que a titulação foi estabelecida pelo método de Mohr, seguindo os conceitos adiantados na titulação anterior e baseando-se na equação 1 e 2 . 


\section{QU MICA}

Os resultados foram anotados no momento em que o primeiro excesso de $\mathrm{Ag}^{+}$ reage com o $\mathrm{CrO}_{4}$ do indicador, como exposto pela equação 1 , e origina outro composto insolúvel que é o responsável pela formação da coloração vermelha e indica o ponto final da titulação, mostrando também um volume estimado para o ponto de equivalência. Confira os resultados do teor de cloreto no gráfico 1 , os valores expostos são produtos da relação de equação de diluição de soluções, que foi desenvolvida a partir dos volumes gastos do reagente $\mathrm{AgNO}_{3}$ em cada uma das titulações, os mesmos estão expostos na tabela 1.

Tabela 2: Volume gasto do reagente $\mathrm{AgNO}_{3}$ nas devidas titulações.

\begin{tabular}{cc}
\hline Amostras de água (Cidades) & Volume gasto de $\mathrm{AgNO}_{3}(\mathrm{~mL})$ \\
\hline Espírito Santo & 0,22 \\
Montanhas & 0,19 \\
Passa e Fica & 0,29 \\
Santo Antônio & 0,31 \\
Várzea & 0,19 \\
Serrinha & 0,60 \\
Lagoa d'Anta & 0,30 \\
Campestre & 0,35 \\
Nova Cruz & 0,32 \\
\hline
\end{tabular}

Gráfico 1: Identificação do teor de cloreto em águas residuais.

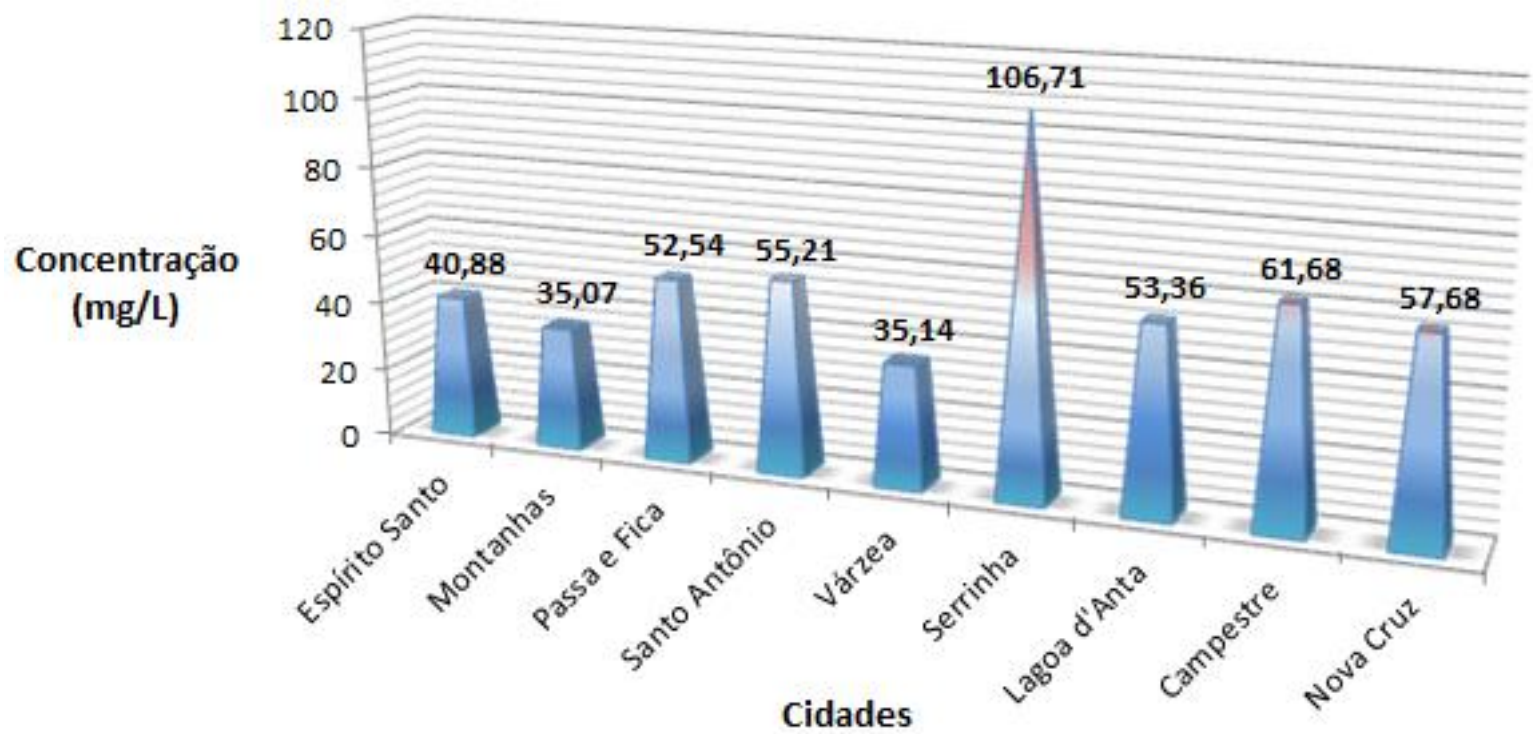

A quantidade de cloreto utilizado no tratamento depende do fornecedor da água, provavelmente algumas cidades podem ter acesso ao mesmo líquido e por isso obteve valores aproximados, como é o caso das cidades de Lagoa d'Anta e Passa e Fica, Montanhas e Várzea, Santo Antônio e Nova Cruz.

É notável que nenhuma das cidades violam a Lei imposta, porém nota-se que na cidade de Serrinha há o dobro do valor de algumas amostras e, mesmo que, esteja dentro do valor permitido há uma concentração tão alta de cloreto que é perceptível um sabor diferente, segundo consumidores dessa água. Além de que os moradores da cidade já 


\section{QU MICA}

haviam constatado algumas irritações na pele que podem ser provenientes da utilização da mesma. As outras cidades possuem uma água de maior confiança, pois quanto menor o contato com o cloreto, menor é o risco provindo desse composto tóxico.

\section{CONSIDERAÇÕES FINAIS}

A realização de uma série de análises feitas permitiu que o objetivo experimental fosse alcançado, chegando a resultados do teor de cloreto que são de interesse a população que utiliza dessas águas em questão. Como também aprimorou os conhecimentos envolvidos no projeto, de modo que a aplicação das teorias envolvidas nas práticas laboratoriais possibilitaram um entendimento mais amplo dos conceitos estudados.

A partir do referido projeto foi possível entender a importância de análises volumétricas, como a titulação que serve para determinar a concentração de algumas soluções e através da mesma pode-se ter resultados significantes de alguns produtos. Após os estudo dos dados obtidos, temos que o teor de cloreto contido nas amostras está dentro dos padrões permitidos, o que é benéfico para a população que utiliza de uma dessas águas.

\section{AGRADECIMENTOS}

Os autores agradecem ao Instituto Federal de Educação, Ciência e Tecnologia do Rio Grande do Norte - IFRN, Campus Nova Cruz pela disponibilização do espaço cedido, por todo conhecimento e experiência desenvolvida na realização do projeto.

\section{REFERÊNCIAS}

1. AFONSO, Carlos; CHAVES, Camille. $\mathbf{O}$ inacreditável emprego de produtos químicos perigosos no passado. Disponível em: < http://www.scielo.br/pdf/\%0D/qn/v29n5/31083.pdf >. Acesso em 02 de agosto de 2016.

2. FUNASA. Fundação Nacional da Saúde. Disponível em: < http://www.funasa.gov.br/site/ >. Acesso em 29 de julho de 2016.

3. MACEDO, Erlane Santana; TEIXEIRA, Eduardo Guimarães; SILVA, Geovane Ferreira. Determinação do teor de Cloreto total na água consumida pelos discentes do IFMACampus Zé Doca (método de Mohr). Disponível em: < http://propi.ifto.edu.br/ocs/index.php/connepi/vii/paper/viewFile/126/1118 >. Acesso em 02 de agosto de 2016.

4. SKOOG, et al. Fundamentos de química analítica. São Paulo: Cegage Learning, 2010. Ed.: Tradução da $8^{\circ}$ edição norte-americana. [Tradução Marco Grassi; revisão técnica Celio Pasquini].

5. BACCAN, Nivaldo; ANDRADE, João Carlos de. Química analítica quantitativa elementar. 3 ed. Edgard blucher, 2001. 